Original Article

\title{
FORMULATION AND EVALUATION OF CELECOXIB CREAM AND ITS RELEASED STUDY
}

\author{
SADIA ANWAR ${ }^{2}$, SYED UMER JAN 1 , RAHMAN GUL ${ }^{1,2 *}$
}

${ }^{1}$ Faculty of Pharmacy and Health Sciences, University of Balochistan, Quetta, Pakistan, ${ }^{2}$ Health Department Government of Balochistan Email: gul.dotani@yahoo.com

Received: 13 Jun 2020, Revised and Accepted: 16 Aug 2020

\section{ABSTRACT}

Objective: The purpose of this study was to formulate and evaluate of Celecoxib cream and it's in vitro release study.

Methods: The release study was conducted, using dialysis cellulose membrane, in Franz cells. The donor chamber was filled with phosphate buffer pH 7.4 , released medium were analyzed by UV-Vis spectrophotometer at $250 \mathrm{~nm}$. Kinetics model was used for calculations. The cream was followed by different evaluations like $\mathrm{pH}$ measurement, homogeneity, spreadability, stability study, drug content, SEM, XRD studies and skin irritation test was used for the reliability of physical conditions and chemical relation. DD solver and SPSS were used for statistical analyzation of the data.

Results: The best in vitro drug release profile achieved with thyme oil in Celecoxib cream. Formulation F2 showed the highest (83\%) released. The results of the Celecoxib (1\%) were suitable in all constraints. The prepared Celecoxib cream was encouraging for the formulation of transdermal drug delivery.

Conclusion: The Celecoxib cream was successfully prepared and could be beneficial for transdermal drug delivery.

Keywords: Celecoxib, Cream, Carbopol 980, Thymol oil, In vitro studies

(C) 2020 The Authors. Published by Innovare Academic Sciences Pvt Ltd. This is an open access article under the CC BY license (http://creativecommons.org/licenses/by/4.0/) DOI: http://dx.doi.org/10.22159/ijcpr.2020v12i5.39757. Journal homepage: https://innovareacademics.in/journals/index.php/ijcpr

\section{INTRODUCTION}

Transdermal drug delivery system (TDDS) is a well define a therapeutic system that delivers for the surface region with a programmed quantity of the drug at a predetermined rate of intact, healthy skin. Under this system, drugs would be provided systemically at a conventional rate and time period and can be extended while sustaining the rate. Therefore, this system of delivering drugs is very helpful in reducing the numerous problems connected with oral treatments like hepatic metabolism at the first level impulsive bioavailability, enhanced first pass, dose inflexibility, residence time at comparatively shorter, dose dumping [1].

At proscribed rate transdermal drug delivery system give an incessant drug percutaneous administration, which allows in systematic circulation eradication of pulse entry, the side effect usually associated with this phenomenon because it permits the termination of medication absorption in therapy that is necessary to be intermittent.

Drug delivery system is designed for therapeutic efficiency, reduce toxicity, to maintain plasma drugs level at a suitable rate through intact skin at a suitable place [2].

The research findings build up a revolutionary theory over a resistant skin barrier, which persuaded many researchers to establish a ratecontrolled drug delivery system which mange transdermal drugs to accomplish the purpose of systemic medication. SKIN with a large surface area covering the body, layered anatomy and defined physicochemical properties are the site of drug administration in case of TDDS depends on the solid nature in the inner phase and on the type emulsion either oil in water/in oil [3].

The research had been conducted on the formulation of topical Ericoid cream. The research had been proclaimed the association of oral administration with the gastrointestinal relater toxicities in the formulation of topical Etoricoxib cream. As Celecoxib was an extremely discerning cyclooxygenase-2 (cox-2) inhibitor like Etoricoxib. Therefore, the current research aims were preparing the Celecoxib Cream by using an active combination of different ingredient. In vitro evaluation incorporated, $\mathrm{pH}$, Stability studies, spread ability, Viscosity, were applied to access the effectiveness rheological properties of the prepared cream, furthermore cell diffusion study skin irritation study and the anti-inflammatory formulation of the cream was evaluated. It was encouraging for the formulation of a topical cream containing Celecoxib, with cyclooxygenase-2 (cox-2) inhibitor [4]

Cream preparation contained a semisolid dosage of one or more drug ingredients spread or dissolved in a suitable base. This period usually has been functional to semisolids that possess a comparatively soft, spreadable uniformity formulated emulsions as moreover water-in-oil or oil-in-water. Though freshly the period has been controlled to the products involving emulsion oil-in-water or aqueous microcrystalline diffusions of long-chain alcohol or fatty acids that are washable water, additional aesthetically and cosmetically suitable. The vehicle as waxes, $50 \%$, hydrocarbons, or polyols. The vehicle known as use for Ointment bases decreases into four general classes [5]

Celecoxib Iannone-Steroidal cyclooxygenase-2 (COX) inhibitors, nonsteroidal anti-inflammatory drugs (NSAIDs), in the case of COX-2 enzyme inhibition it exhibits Anti-inflammatory, antipyretic action and analgesic action. In musculoskeletal disorders management of pharmacology. Celecoxib has recognized the worth in Clinical experiment of Celecoxib in acute spondylitis, gouty arthritis, rheumatoid arthritis, ankylosing, Osteoarthritis, dysmenorrheal, pain in the lower back. Rheumatoid arthritis (RA) term was explained in 1859 by "Sir Alfred Baring Garrod". RA is a chronic disease that becomes the cause of swelling, pain, stiffness in joints and can cause disabilities and have a negative socioeconomic impact [6].

Celecoxib and other COX-2 selective inhibitors, mavacoxib, parecoxib, and valdecoxib, were discovered by a crew at the Searle partition of Monsanto by John.

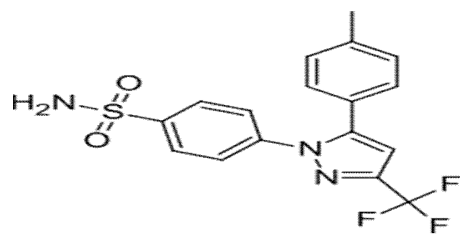

Fig. 1: Celecoxib structural formula 


\section{MATERIALS AND METHODS}

\section{Chemicals}

Celecoxib, Triethanolamine, Sorbian monooleate (Tween 80), Propylparaben, polyoxymethylene (80), thymol oil, Cetostearyl Alcohol, liquid paraffin, white petrolatum, Carbopol 980 NF polymer, De-ionized water and glycerin.

\section{Equipment's}

UV-Spectrophotometer double beam (Shimadzu 1601), pH meter (JENWAY 3510), Digital weighing balance (Sartorius), Auto Reverse Magnetic Stirrer (Gallen Kamp "Registered Trade Mark") made of England, Franz diffusion Cell, Hot plate and Stirrer (JENWAY 1000)
Programmable Rheometer, XRD, Water distillation apparatus (AUTOSTIU Freshman-4), Tewa meter SEM, Refrigerator, Oven and incubator,Conical flask 50-100 ml, Glass beaker 50-100 ml, Pipette 10 $\mathrm{ml}$, Amber colored glass jar, aluminum foil and White-colored glass.

\section{Celecoxib calibration curve}

To establish Celecoxib standard curve, a solution in stock was come about in $10 \mathrm{mg}$ of Celecoxib powder, dissolved in ethanol $(50 \mathrm{ml})$ through the stirring of multiple minutes and accomplishing $100 \mathrm{ml}$ volume in ethanol further diluted in phosphate buffer contains $\mathrm{CH}$ 7.4). From the stock solution, dilutions were made as $0.003,0.006$, $0.009,0.018$ and $0.036 \mathrm{mg} / \mathrm{ml}$. At $250 \mathrm{~nm}$, ultraviolet (UV)-visible spectrophotometer (Shimadzu UV-1601, Japan) was employed and absorbance of entire dilutions were analyzed. The graph for linearity is delineated in fig. 2 .

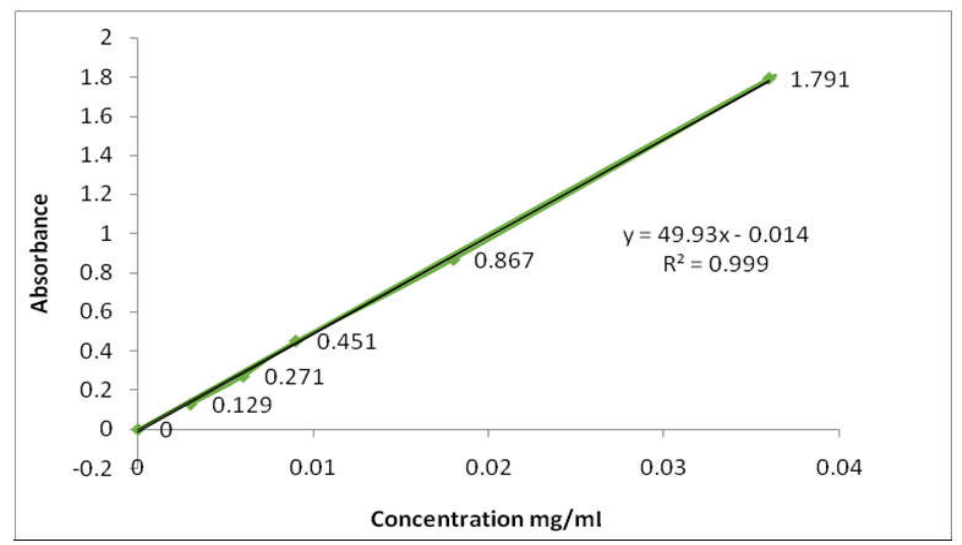

Fig. 2: Calibration curve of celecoxib

\section{Preparation of celecoxib cream}

The formulation of Celecoxib cream followed the preparation formulation of the researcher Razi Ullah et al. [7]. 75 the heat was used for heating the aqueous and oil phases over a water bath in a beaker. Carbopol 980, Tween-80, White Petrolatum, Cetostearyl Alcohol and Liquid Paraffin was comprised in oil phase Glycerin, De-ionized water and Triethanolamine was composed in the aqueous phase
In the beginning, the speed was at homogenizer at 2000rpm for 20 min, with continuous stirring aqueous phase Dropwise added to the oil phase. After 20 min the speed was decreased to $1000 \mathrm{rpm}$ of the homogenizer for a further 5-10 min. the speed of homogenization was further reduced to 500rpm during the last extended $5 \mathrm{~min}$. in the process has resulted in the formulation of Celecoxib cream. As shown in table 1 [8]

Table 1: Formulation of celecoxib cream

\begin{tabular}{lll}
\hline S. No. & Ingredients & Composition \\
\hline 1 & Celecoxib & $1 \mathrm{~g}$ \\
2 & Thyme oil & $1 \mathrm{~g}$ \\
3 & Cetostearyl Alcohol & $10 \mathrm{~g}$ \\
4 & White Petrolatum & $5 \mathrm{~g}$ \\
5 & Tween 80 & $8 \mathrm{~g}$ \\
6 & Liquid paraffin & $5 \mathrm{~g}$ \\
7 & Carbopol 980 & $0.60 \mathrm{~g}$ \\
8 & Glycerin & $6.0 \mathrm{~g}$ \\
9 & Triethanolamine & $1.5 \mathrm{~g}$ \\
10 & De-ionized water & $62 \mathrm{~g}$ \\
\hline
\end{tabular}

\section{Evaluation of celecoxib cream}

\section{Physical evaluation of cream}

The physical evaluation would include studies of In vitro drug diffusion, $\mathrm{pH}$ determination, Spreadability, homogeneity on Celecoxib cream.

\section{Determination of $\mathbf{p H}$}

For measurement of $\mathrm{pH}$ in the formulation of Celecoxib cream Digital $\mathrm{pH}$ meter was used. The $\mathrm{pH}$ buffer solution was used for calibration [9]

\section{Spreadability}

The spread ability experiment was accomplished by two glass slides. A cream is sandwiched in between these glass slides. In this procedure $0.5 \mathrm{~g}$ formulation was kept above the first glass slide and $10 \mathrm{~g}$ was kept on the second slide until no further probable spreading. The diameter of escalated circle was measured and defined as spread ability proportional values [10-12]

\section{Analytical method}

The standard weight of the solution is prepared by dissolving the exact weight of ethanol in $50 \mathrm{mg}$ of Celecoxib properly balanced on 
an analytical balance and solvent mixed in a volumetric flask. The formulated solution is than filtered by membrane filter. Then absorbent of solution is checked by taking it to UV visible spectrophotometer. A Sample of $100 \mathrm{ml}$ volume solution is prepared by dissolving ethanol in $5 \mathrm{~g}$ of the Celecoxib cream. Later the solution is filtered and $50 \mathrm{ml}$ ethanol is made by taking $1 \mathrm{ml}$ of the solution. Absorbance of the solution is measured at $250 \mathrm{~nm}[13,14]$.

\section{Skin irritation study}

In Skin irritation study the formulated Celecoxib cream has practical over the smooth-shaven skin of the rabbit in the area of nearly 6 $\mathrm{cm}^{2}$ for an hour and patch of semi-occlusive gauze was used for protecting. After the experimental duration the skin of the rabbit was checked by removing cream from the skin and it was found clear and in harmful. For further verification the same experiment was repeated regularly $7 \mathrm{~d}$ for an hour and all observed reactions had recorded (table 2) [15]

\section{SEM}

Scanning electron microscopy (SEM) was applied for tropical Celecoxib cream surface morphology. The shape, morphology and size of the particles was checked and described by SEM studies were done. In the measurement process of SEM adhesive double-sided tape was used for attaching the prepared formulation on the metal stub. The formulation was passed through a vacuum chamber for drying and then $10 \mathrm{~nm}$ thick gold layer was used for sputter-coating and observed in SEM high resolution. (JSM-840, Joel Instrument, Tokyo, Japan) [16].

\section{XRD}

The technique rapidly used for analyzing powder diffraction is X-ray diffraction (XRD). XRD is one of an indispensable technique for quality control, crystalline material phase identification and classification of materials. Through XRD information is generated on unit cell dimension. For pure drug and physical mixture comparison, power XRD studies display samples. To investigate Celecoxib amorphous nature and crystalline, 5 to $50{ }^{\circ} \mathrm{C} \mathrm{X}$-rays diffractograms powdered were used at $2 \theta$ [17].

\section{In vitro diffusion studies procedure}

Franz diffusion cell apparatus (Perm Gear, USA) was used to perform the procedure. The dialysis cellulose membrane has a $05 \mathrm{ml}$ compartment between receptor and donor and held in the Franz diffusion cell apparatus. The receptor compartment chambers were filled with $5 \mathrm{ml} \mathrm{pH} 7.4$ phosphate buffer and Celecoxib cream was used and the cream comprising $1.0 \%$, thyme oil. During the experiment the solvent temperature was stable at $37{ }^{\circ} \mathrm{C}$ The procedure was continued for twenty-four hrs with the gap at $0.5,1$ $1.5,2,3,4,8,12,16,20$, and $24 \mathrm{~h}$. From the cell receptor compartment, $1.0 \mathrm{ml}$ sample was drawn out at predetermined time and immediately fill up with the same volume of buffer at $37{ }^{\circ} \mathrm{C}$ [18]. The withdrawn samples were filtered and the Celecoxib absorption was measured at $250 \mathrm{~nm}$ UV-visible spectrophotometer.

\section{In vitro release kinetic studies of celcoxib cream}

Through a spectroscopy technique, the impregnate quantity of drug was identified and calculated. At that instant when drug amount (mg) in the receptor medium (sample) was taken and observed (0$24 \mathrm{~h}$ ). The linearity regression study and release criterion of the drug impregnation for every formula were evaluated. To determine the release of drug and impregnation of a drug by a dialysis celleolse membrane, correlation coefficient $(r)$ was valued by calculations just to show the case of drug release and impregnation is a zero order first order, Higuchi, Korsmeyer-Peppas, or follows Hixon-Crowel diffusion release model. This is done for each formula. Entire calculations were executed with respect to the subsequent kinetics equations accomplishing a validated software program, DDSolver for Microsoft Excel 2007 [18]

$\begin{array}{lll}\text { Model } & \text { Equation } & \\ \text { - Zero order } & \mathrm{Qt}=\mathrm{Q} o+\mathrm{Kot} & 1 \\ \text { - First order } & \mathrm{In} \mathrm{Qt}=\ln \mathrm{Q} o+\mathrm{K} 1 \mathrm{t} & 2 \\ \text { - Higuchi } & \mathrm{Qt}=\mathrm{K} \mathrm{H} \sqrt{\mathrm{t}} & 3 \\ \text { - Korsmeyer- } & \mathrm{Mt} / \mathrm{M} \infty=\mathrm{Ktn} & 4 \\ \begin{array}{l}\text { Peppas plot } \\ \text { - Hixon-Crowell }\end{array} & \mathrm{Qt} / \mathrm{Qo}=\mathrm{Kktn} & 5\end{array}$

\section{Stability studies of celecoxib cream}

Stability studies on the preparation of Celecoxib cream was continued and completed over $03 \mathrm{mo}$ at $25 \pm 1{ }^{\circ} \mathrm{C}$ and $40 \pm 1{ }^{\circ} \mathrm{C}$. The analyzation of the cream was done by UV-Visible Spectrophotometer and during $03 \mathrm{mo}$ all the tests were done physically at every month such as $\mathrm{pH}$ measurement, homogeneity and Celecoxib cream formulation evaluation was done after 3 mo of topically prepared $[19,20]$.

\section{Statistical analysis}

The artificial cell membrane was analyzed by performing Anova test on SPSS Software. Different kinetic modes was used with DD solver for drug release kinetic for transdermal cream $[19,20]$.

\section{RESULTS AND DISCUSSION}

The $\mathrm{pH}$, homogeneity, spreadability, drug content of celecoxib formulation and consistency were identified (table 2). The formulations were equivalent in aspect of their, liquefaction, color and further parameters were satisfying likewise $\mathrm{pH}$. The formulations exhibited $\mathrm{pH}$ in between (5.1 and 6.2) compatible to $\mathrm{pH}$ examined in previous studies of formulations of Celecoxib cream topically with respect to normal human skin $\mathrm{pH}$ range (4.5 to 6.5) [18]. Spreadability and consistency were examined during a period of $90 \mathrm{~d}$. Homogeneity was ensured with absence of lumps. Drug content of Celecoxib cream was in span of $98.10-99.11 \%$ and celecoxib cream has shown good existence of uniformity. Application of the gels to rabbit skin for $7 \mathrm{~d}$ resulted in no redness, lesions, or itching, indicating that they were not irritating to the skin. Total physical evaluated parameters suggest convenient results for transdermal application. By performing stability studies for 3 mo (90 d) at $25 \pm 1{ }^{\circ} \mathrm{C}$ and $40 \pm 1{ }^{\circ} \mathrm{C}$ results achieved were satisfying and ensured that Celecoxib cream is good enough at $\left(25 \pm 1^{\circ} \mathrm{C}\right)$. The end of $3 \mathrm{mo}$, it is also clearly seen from results of standard deviation that at $40{ }^{\circ} \mathrm{C}$ standard deviation is slightly greater and it was aside from normal and appropriate ranges whereas $25 \pm 1^{\circ} \mathrm{C}$ standard deviation was smallest and it fell into sufficient range. So it arrived at a judgment that at $25 \pm 1{ }^{\circ} \mathrm{C}$ formulations predicts the standards required for preparation of Celecoxib cream, which is the matter of interest in extent stability studies. In this study, (dialysis cellulose membrane) were taken, statistically, it was observed that the membranes have good released. The formulation (F2) showed the maximum released $(83 \%)$. This study is compatible with earlier works of Gul et al. [19] who gave a detailed account in words about the discharge of ephedrine in semi soild dosage forms. The data of each formulation was put to the first order as shown in table 3 . Permeation model. Discharge of Celecoxib from the transdermal formulation, and its release through the membrane of cellulose, are delineated in fig. 3.

Table 2: Physical parameters values for celecoxib cream formulations

\begin{tabular}{llllll}
\hline $\begin{array}{l}\text { Celecoxib cream } \\
\text { formulations }\end{array}$ & $\begin{array}{l}\text { Spreadability } \\
\text { (g. cm/s) }\end{array}$ & pH & $\begin{array}{l}\text { Skin } \\
\text { irritation }\end{array}$ & Homogeneity & Drug content (\%) \\
\hline F1 & 4.4 & 5.2 & NO & Good & 98.10 \\
F2 & 4.8 & 5.9 & NO & Good & 98.12 \\
F3 & 4.7 & 6.2 & NO & Good & 99.11 \\
F4 & 5.2 & 5.8 & NO & Good & 98.13 \\
F5 & 5.4 & 6.3 & NO & Good & 98.28 \\
\hline
\end{tabular}




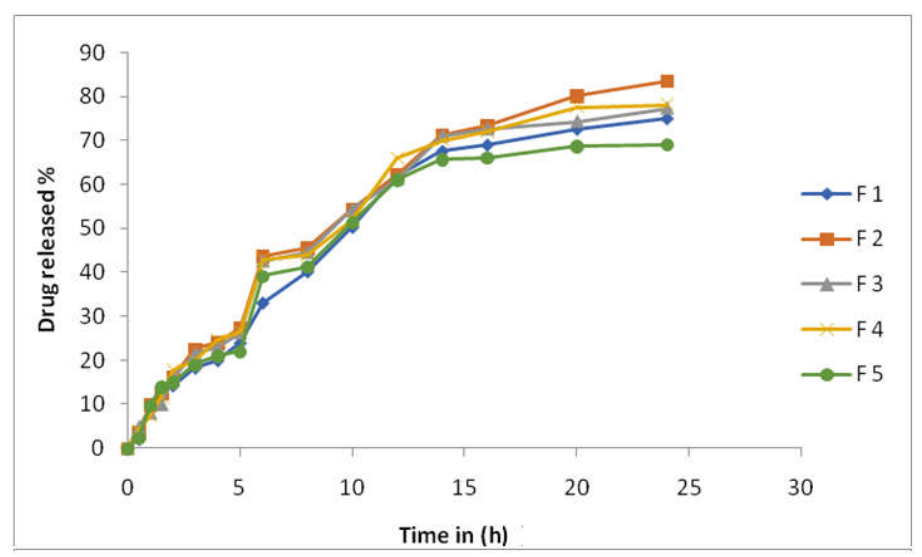

Fig. 3: Release of celecoxib cream $1 \%(\mathrm{~W} / \mathrm{V})$ via dialysis cellulose membrane

Table 3: Celecoxib release from the formulations by using dialysis cellulose based membrane

\begin{tabular}{|c|c|c|c|c|c|c|}
\hline \multicolumn{7}{|c|}{$\left(R^{2}\right)$ is the coefficient correlation } \\
\hline Formulation type & Zero $(0)$ order & First (1st) order & Higuchi & Hixon-crowell & Korsmeyer peppass & Best-fitting model \\
\hline F1 & 0.8790 & 0.9831 & 0.9276 & 0.9747 & 0.9630 & First order \\
\hline $\mathrm{F} 2$ & 0.8742 & 0.9912 & 0.94279 & 0.9845 & 0.9766 & First order \\
\hline F3 & 0.8446 & 0.9841 & 0.9384 & 0.9703 & 0.9609 & First order \\
\hline $\mathrm{F} 4$ & 0.8507 & 0.9848 & 0.9390 & 0.9732 & 0.9629 & First order \\
\hline F5 & 0.8151 & 0.9654 & 0.9302 & 0.9433 & 0.9462 & First order \\
\hline
\end{tabular}

\section{XRD studies}

X-ray diffraction studies were applied to endorse chemical and physical properties of Celecoxib and Celecoxib cream fig. 4 (a), showed fine peaks of diffraction at a value of $13.51^{\circ}, 17.23^{\circ}$, and $20.18^{\circ}$ etc at an angle of $2 \theta$. X-ray diffractograms are positioned in (fig. 4 a) Showed crystalline nature of Celecoxib, while fig. 4(b) shows no peak of blank Celecoxib, which was reported by Sami et al. previously. In fig. (c) Celecoxib cream displayed peaks having minor intensity, while fused peaks were displayed in diffractograms of the Celecoxib cream. Irregular peaks of Celecoxib demonstrated that the drug changed into an amorphous type in cream with a molecularly discrete nature.

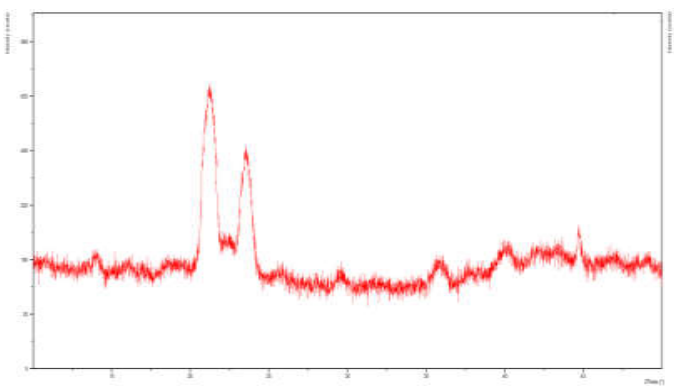

(a)

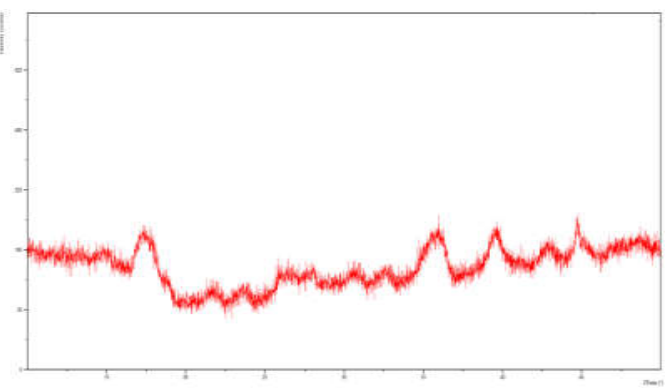

(b)

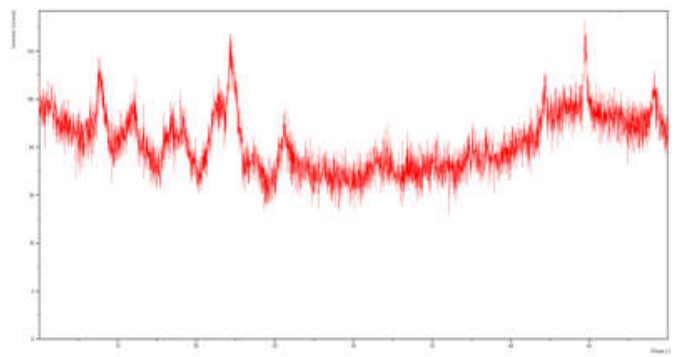

(c)

Fig. 4: X-ray diffractograms of Celecoxib drug (a), blank cream (b) and Celecoxib cream formulation (c)

\section{SEM}

The surface morphology of the Celecoxib drug was studied under an electron microscope. Fig. 5(a) showed irregular shapes was observed under an electron microscope because the polymer used was watersoluble in nature. SEM results showed in fig. $5(\mathrm{~b}, \mathrm{c})$ that the drug used in cream, was almost the same and not affected in formulations. 


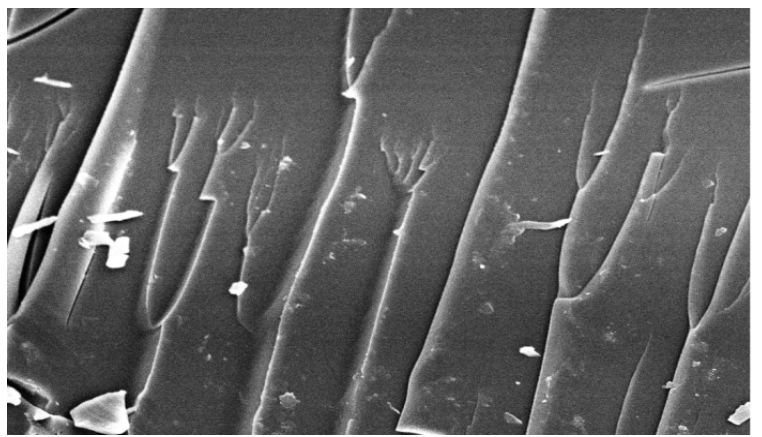

(a)

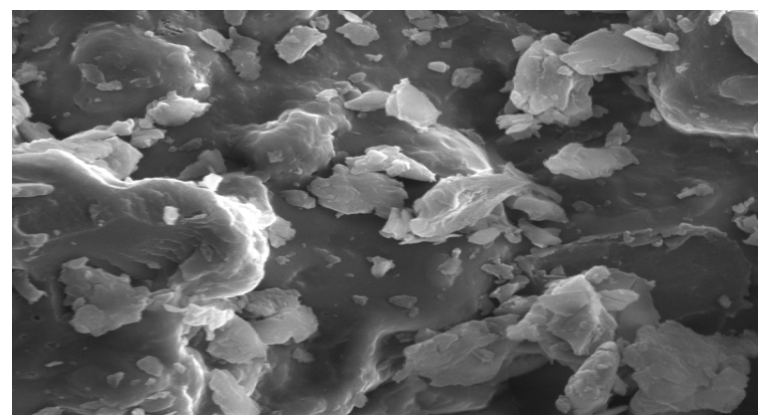

(b)

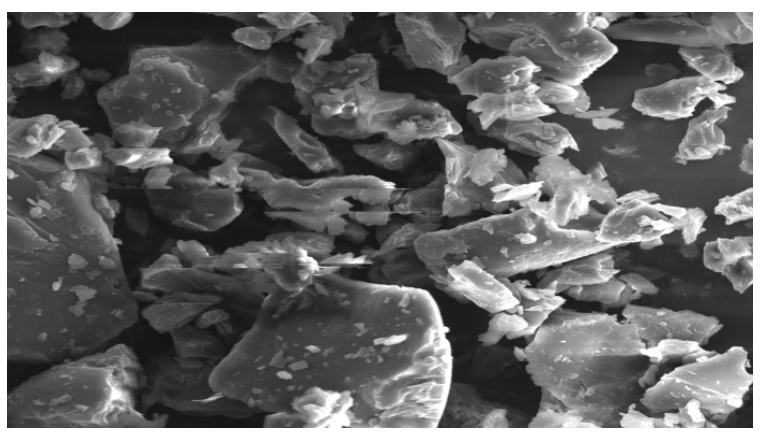

(c)

Fig. 5: Displays polymeric cream-based surface morphology only (a), different magnification powers exhibits surface morphology of Celecoxib cream (b, c)

\section{CONCLUSION}

In this study, novel Celecoxib cream formulations as transdermal delivery were developed. Celecoxib as a component of the cream has a good affinity for the celleulose membrane, and thymol oil showed good enhancement of drug released in the dialysis cellulose membrane. The statistical data showed the formulations were physicochemically stable. An in vitro release studies significantly showed that the optimized formulations data together promote the suggestion that Celecoxib cream formulations showed potential novel delivery systems to improve the release and stability of Celecoxib

\section{ACKNOWLEDGEMENT}

We are thankful to the Dean, Faculty of Pharmacy and Health Sciences, University of Balochistan for providing laboratory facilities and Health Department, Government of Balochistan for their timely support to outright this research.

\section{FUNDING}

\section{AUTHORS CONTRIBUTIONS}

We submit a manuscript entitled: "Formulation and evaluation of celecoxib cream and its released study" author by Sadia Anwar, Syed Umer Jan and Rahman Gul for the consideration for the journal as a research paper in the journal Asian Journal of Pharmaceutical and Clinical Research. Sadia Anwar, Rahman Gul analyzed the laboratory work, analyzed the data, and wrote the manuscript. All authors read and approved the manuscript. All authors are the guarantors

\section{CONFLICT OF INTERESTS}

We have no conflict of interest for publication this paper. Authors have not received any funding.

\section{REFERENCES}

1. Roy S. Preformulation aspects of TDDS, thomas spencer, preclinical assesssment of TDDS. In: TapanGhosh, William Pfister, Su Yum. (Editors). Transdermal and Topical Drug Delivery Systems Interpharm Press; 1997. p. 140-58.

2. Barry BW. Transdermal drug delivery manufacture of medicines. Michael Aulton (Editor). $3^{\text {rd }}$ ed, Churchill Livingston, Elsevier; 2007. p. 566-74, 592-5.

3. Sharma Y, Jeyabalan G, Singh R. Potential wound healing agents from medicinal plants: a review. Pharmacologia 2013;4:349.

4. Hofland HE, Van der GR, Bodde HE, Junginger HE, Bouwstra JA. Estradiol permeation from nonionic surfactant vesicles through human stratum corneum in vitro. Pharm Res 1994:5:659-64.

5. Ueda CT, Shah VP, Derdzinski K, Ewing G, Flynn G, Maibach H, et al. Topical and transdermal drug products. Pharmacopeial Forum 2009;3:750-64.

6. Prajapati ST, Patel CG, Patel CN. Transfersomes: a vesicular carrier system for transdermal drug delivery. Asian J Biochem Pharm Res 2011;2:507-24.

7. Razi M, Ullah K. Formulation and in vitro evaluation of cream containing diclofenac sodium and curcuma longa for the management of rheumatoid arthritis. Int J Pharma Sci 2014;4:654-60.

8. Khan M, Hussain R, Raza MS, Nazir SR. Formulation development evaluation and anti-inflammatory effects of etoricoxib cream. Indo Am J Pharm Res 2014;10:3945-52.

9. Chakole CM, Shende MA, Khadatkar SN. Formulation and evaluation of novel combined halobetasol propionate and fusidic acid ointment. Int J Chem Tech Res 2009;1:103-16.

10. Fathy A, Dawaba $H$, Ahmed $M$, Ahmed S. Preparation, characterization, and stability studies of piroxicam loaded microemulsions in topical formulations. Drug Discoveries Ther 2010;4:267-75.

11. Rahman G, Syed UJ, Mahmood A, Muhammad A, Muhammad MQ. Formulation, characterization and in vivo evaluation of hedera helix l., topical dosage forms Pak. J Pharm Sci 2019;6:2603-8.

12. Avish DM, Swaroop R. Lahoti formulation and evaluation of ointment containing sunflower wax. Asian J Pharm Clin Res 2019;8:115-20.

13. Muruganantham V, Prabakaran M, Pasupathi C, Peely LR, Pooja B. Formulation and evaluation of microemulsion gel for transdermal delivery of tramadol. Asian J Pharm Clin Res 2019:5:251-9.

14. Sharma CP. Interpolymer complex microparticles based on polymethacrylic acid-chitosan for oral insulin delivery. J Appl Polymer Sci 2006;2:506-12.

15. Trivedi M, Patil S, Mishra RK, Jana S. Structural and physical properties of biofield treated thymol and menthol. J Mol Pharm Org Process Res 2015;2:127.

16. Samiullah, Syed UJ, Rahman G, Syed J, Asmathulla. Formulation and evaluation of transdermal patches of pseudoephedrine HCL. Int J Appl Pharm 2020;3:121-7.

17. Vedavathi T, Srinivasa RB. Formulation and evaluation of terbinafine hydrochloride microsponge gel. Int J Appl Pharm 2019;6:78-85

18. Gul R, Jan SU, Ahmad M, Faridullah S, Akhtar M. Formulation and evaluation of topical carbamazepine semi-solid dosage forms for transdermal drug delivery. Lat Am J Pharm 2019;1:121-7. 
19. Gul R, Jan SU, Ahmad M, Faridullah S, Akhtar M. Formulations, characterization, in vitro and ex vivo release of Ephedra extract from topical preparations using dialysis cellulose membrane and natural rabbit skin. Dissolution Technol 2017;24:24-30.
20. Rahman G, Syed UJ, Mahmood A, Syed F, Muhammad A. Extraction, formulation and characterization of an in vitro and ex-vivo evaluation of thymus serpyllum L. (Thymus oil) from topical preparations using dialysis cellulose membrane and natural rabbit skin. Pak J Pharm Sci 2019;4:1563-70. 